\title{
Performing Age(ing): A Lecture Performance
}

\section{Prologue}

This text is the written version of a 30-minute long lecture performance on images and narratives of age(ing) from a contemporary dance perspective. ${ }^{1}$ I developed this lecture performance for the international symposium "Cultural Perspectives on Ageing" in Hanover, Germany and performed it there on November 29, 2018. As a researcher on the subject of dance and age(ing) with a practice-as-research approach (Nelson 2013) - usually called "artistic research" in continental Europe (Borgdorff 2006) - it is my concern that my performative, embodied practice and artistic methodology is visible in my academic research. In the lecture performance, therefore, my live dancing body played quite an important role. To retain the performance-based form of the lecture in this publication, I have integrated into my text both the verbal contents of the lecture and short descriptions of my actions and dances, in a similar manner that stage directions are included in dramatic text. The photos taken by age researcher Peter Derkx during the performance offer important additional information. Even though such photos do not convey the dynamics of the actual dancing, they do give an indication of the aesthetics of the overall event.

\section{Warm-up}

The symposium participants enter a spacious lecture space with two rows of chairs in a wide semi-circle. While they find their seats, I test and explore my dancing body and the space. During my improvised dance exploration, I say something like the following:

1 I work with the term "age(ing)" throughout this text. My understanding of 'age(ing)' is influenced by the writings of the German age researcher Miriam Haller, who works with the terms “Alter(n)" and "Alter(n)sstudien” (2010, 2013). The use of brackets in her work emphasizes that her field of inquiry is not limited to old age. In addition, I see the use of brackets as an intentional stumbling block, thus rendering the often-used word "aging” unfamiliar. Indeed, the brackets accentuate the fact that aging is the gerund of age. As such, they show that aging is not a discrete period of life - as, for example, in the much-used phrase "an aging woman" - but rather a continuum. I suggest that the brackets open the word 'aging' to multiple meanings.

Ә OpenAccess. () 2021 Susanne Martin, published by De Gruyter. (cc) BY-NC-ND This work is licensed under the Creative Commons Attribution-NonCommercial-NoDerivatives 4.0 International License. 
This is a warm-up dance. It is my time to get used to moving my body in your presence. It is also your warm-up time: a transition, a moment to find the right channel inside of you to receive this kind of information. This information is called contemporary dance. So, you warm-up and seek the frequency for this special edition of contemporary dance (gesturing at my moving body). And I warm up to dance here and now in front of you and for you. And I bring the air into motion a little bit. Maybe that helps.

By the way, my presentation does not focus on old age, but on age(ing) as a lifelong process.

\section{Dancing Age(ing)}

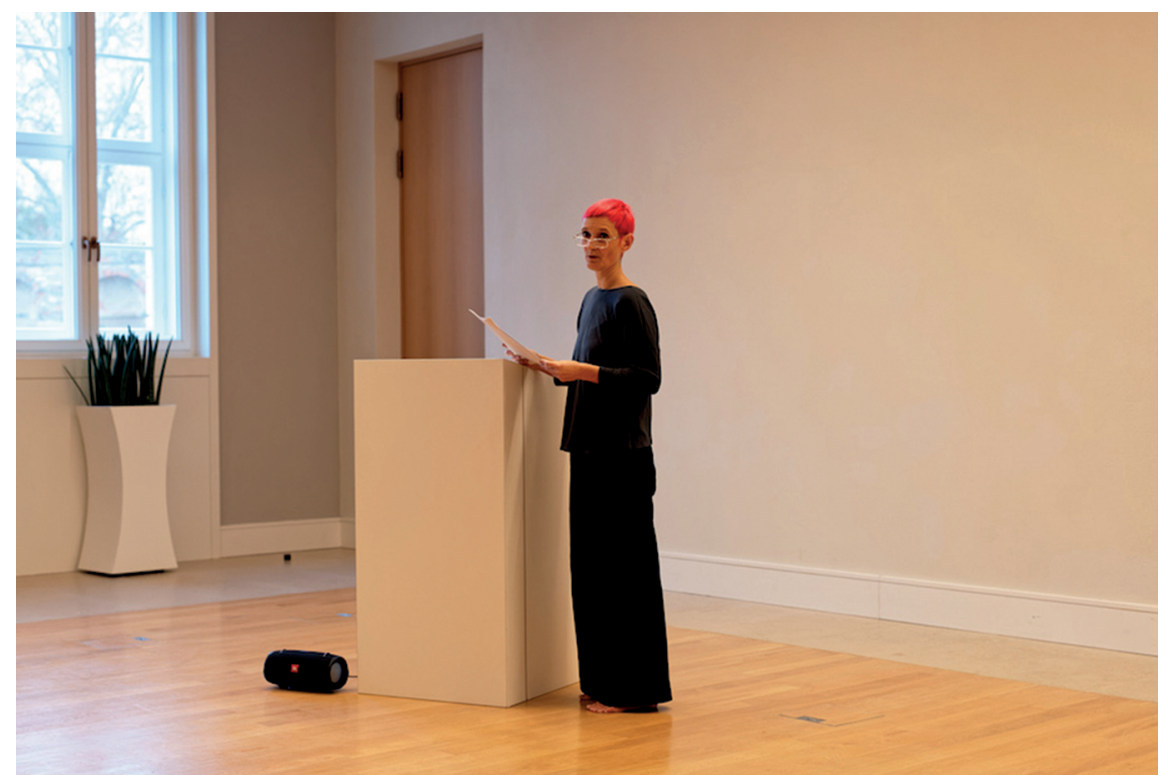

Figure 1: At the lectern, photo: Peter Derkx]

Getting installed at the lectern, reading from my script:

I'm a dancer who makes choreographies; I'm a choreographer who improvises; I'm an improviser who earned a $\mathrm{PhD}$ for a research project that is called Dancing Age(ing). Dancing Age(ing) has now transformed into a book (2017). But it is also an extensive video collection that documents the practical artistic 
research process, as well as two stage performances. Taken together, all of this material asks the following questions:

- How can dance intervene in our age(ing) culture?

- What alternative ways of both doing age(ing) (Swinnen and Stotesbury 2012) and representing age(ing) can dance provide?

- How might dance relate to the tension arising from the fact that we, in postindustrial societies, get older and older, while the need to stay productive, at peak performance levels, and perfectly functioning keeps increasing, together with a neo-liberal decrease in social security systems and practices of solidarity (Formosa 2013)?

Dance has a strong tradition of celebrating youth and youthfulness. Accordingly, a number of studies show that the majority of professional dancers transition out of their performance careers in their early to mid-thirties (Baumol et al. 2004; Dümcke 2008; Dickinson 2010; Levine 2005; Schwaiger 2012; Wainwright and Turner 2006a, 2006b). However, dance - and specifically contemporary dance - is also a site for questioning and inventing new ways of experiencing and presenting human bodies in movement, and for questioning and dismantling stereotypical body and age-related values and images (Benjamin 2010; Brayshaw and Witts 2014; Hoghe 2005; Albright 1997).

In Dancing Age(ing), I describe two interesting territories in contemporary dance practice that offer a critique of ageism and follow alternative pathways of doing age(ing) and representing age(ing). The first is improvisation practice.

Among dance artists whose work is improvisation-based, what I see most often and what is most convincing in terms of critiquing ageism is a continuity of practicing and performing dance throughout midlife. I identified specific strategies within the field of improvisation that support a potentially life-long physical creative practice, which also means to do and possibly to conceptualize age(ing) differently. I looked at colleagues of mine above the age of fifty, at their doing, thinking, and practicing as expert improvisers, and I also looked at my own improvisation practice. I found strategies at work that keep the practice alive and developing, that keep us interested and deeply engaged, and that keep us financially sustained as performing artists. In summary, these strategies focus on:

- Establishing working and exchange structures on the fringes of the art market,

- Dealing with ever-changing physical constraints within the practice, and

- Practicing reflexivity. 
The second territory I examined is performance. By that I mean these moments of showing dance in public. I analyzed a range of current dance works and created two performances myself as result of my research. They are called: The Fountain of Youth (2013) and The Fountain of Age (2015). This approach allowed me to articulate four specific strategies for presenting alternative images, imaginations and representations of age(ing) to an audience. These are:

- Resisting the youthfulness of dance

- Reconciling with age(ing) and death

- Colliding with age norms

- Ambiguating age(ing).

I argue that dance pieces with an "age-critical” (Martin 2017, 14) or "anocritical” (Maierhofer 2007, 23) impetus employ one or several of these strategies. Today, I will not expand on the categories through which I analyze improvisation practice and performance strategies. However, I trust that the keywords above will resonate and inspire your thinking as I now give you some more concrete insights into my own age-critical performance making.

\section{Performance excerpts from JULIO}

\subsection{Introduction}

While my theoretical engagement with age(ing) on and off stage started with my $\mathrm{PhD}$ project, my choreographic examination of age(ing) started quite a few years earlier. I have been making performance pieces around questions of age(ing) since 2003. Between 2003 and 2009 I created two larger performance series in a rather theatrical style (JULIO, 2003-2006 and Rosi tanzt Rosi, 2007-2009). By this I mean that I developed characters older then myself and imagined their biographies. Each of these characters had a specific style: their own way of dressing up and of being in the body, a specific muscle-tone, a certain rhythm, a particular taste in music, and an idiosyncratic way of dancing. I would like to show you two examples: two excerpts from the JULIO series that I made in my mid-thirties.

On a biographical level, the characters staged in these two solos were visions of my own future, if a few things in my life had turned out differently. On a cultural level, it was a great discovery and a pleasure for me to embody these dance amateurs who were a bit older, less attractive, and less confident than I thought I could allow myself to be as a dancer and choreographer. The work thus allowed me to recognize and reflect upon the expectations and fears around age(ing) 
within my own contemporary dance milieu. The solo Herr K. Müh is twenty minutes long and the solo Claudia is thirty minutes long. Both solos start with quite a stereotypical embodiment of gendered age(ing), but over the course of the pieces, both characters gain greater physical, social, and emotional complexity. Here and now, I can show you only these beginnings. I just hope that some of the density and depth of the characters comes through in these excerpts.

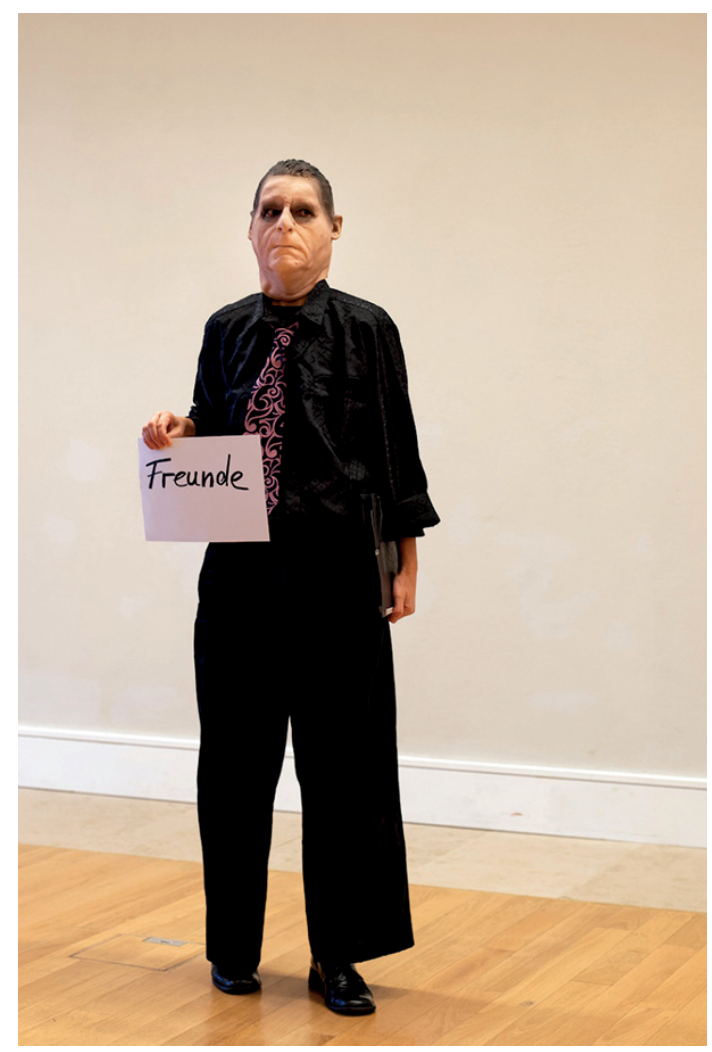

Figure 2: First excerpt from the performance series JULIO, photo: Peter Derkx]

\subsection{Herr K. Müh}

I go to the chairs with props placed on one side of the informal stage area, change into a black shirt, shoes and tie, put a male mask over my head and take a folder 
with me. Back in the space I take sheets of paper out of the folder, marked: AMIGOS; FREUNDE. Then begins an old-school masculine style of gymnastics: moving shoulders, neck and head in an abrupt, jerky mode; hard stretches of thigh and achilleas; side-bends, knee-circles, back-bends and elbow-pushups. I switch on music. While Charles Aznavour sings "Yesterday when I was young", I go back to the folder, where I find other marked sheets to hold up: I NEED TO EXPRESS MYSELF; NOW A SPONTANEOUS IMPROVISATION; FOR CLAUDIA. Then, in a corner, some ritualistic movements of preparation are followed by an energetic but arrhythmic moving through the space. After a while, this slows down, with more gestural moves and less fighting with the rhythm of the music. Then, passionate moving on the spot and more virtuosic knee-circles. Then a rather disillusioned walk towards the back wall until the music ends. I go back to the chairs, remove the shirt, shoes and mask. The song repeats itself.

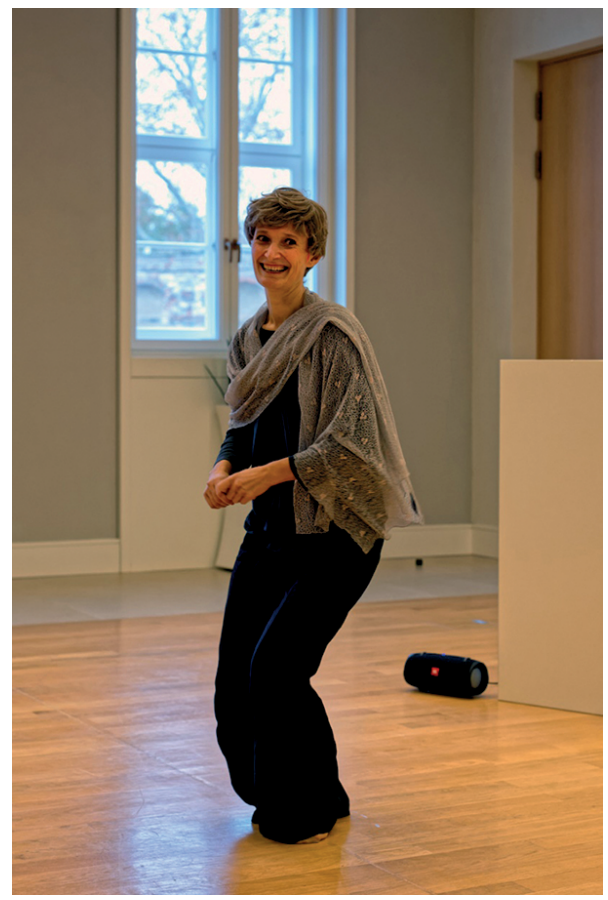

Figure 3: Second excerpt from the performance series JULIO, photo: Peter Derkx] 


\subsection{Claudia}

I put on skin-colored nylon socks, a short grey wig, a light scarf, and move closer to the audience to speak with nervous enthusiasm over the music - the Charles Aznavour song is still playing.

My name is Claudia, I think I will do my dance right away, then it's done, yeah?

I begin, a bit shyly, to move to the music.

The music is a bit heavy, a bit sad; I think I have something else.

I change the music at the lectern. Now we hear Julio Iglesias singing "Begin the Beguine”, by Cole Porter.

This is Julio Iglesias, I like him, I have been to three of his concerts - they were very, very special.

I start a kind of party dance in the center of the space, elastically and in tune with the music but at the same time nervously fluttering, with interruptions of very nervous and embarrassed laughing. Finally, I break off with shrill laughter, running to the lectern to switch off the music.

Enough, too much, so embarrassing.

I go to the chairs, take off the wig, scarf and nylon socks, then continue the lecture at the lectern, reading from my script.

\subsection{Analysis and contextualization of the performance excerpts}

Looking back at these works I would say I was working on habitus, and how biography becomes inscribed in the body (Bourdieu 1987). I let each of these characters collide with or break away from the normative script of their age-biography (Gullette 2004). In other words, I worked with the performativity of age(ing), and the intersection of age and gender performativity (Woodward 2006). I learned a lot from that.

From K. Müh, the male character Klaus, I learned how relieving and enjoyable it was when I found a way to expose and artistically exploit the stiffness, sadness and tiredness I actually really felt at the time I made this piece. It was the fact of changing my face and playing with the ambiguity of the double image of male and female, older and younger, that gave me permission to do so.

From Claudia I learned how disempowering it is to move in slippery nylon socks and how energizing it is to have a three-minute rock 'n roll freak-out to cheesy music. This is learning through practice. Later I learned to theorize the context-, culture-, and class-specific fine distinctions between what is adequate 
and appropriate, and what is inadequate and inappropriate for, let's say, a petitbourgeois middle-aged woman like Claudia (Bourdieu 1987). Claudia and Klaus move inside traditional gender roles and gender requirements. But they are also in the moment of moving themselves out of these. A bit clumsy still, and with a big portion of vulnerability, they are exposing themselves to ridicule.

\section{Performance excerpt from The Fountain of Youth}

\subsection{Introduction}

In the performance The Fountain of Youth (premiered 2013), which is part of my doctoral thesis, I do not work with characters, and I am not performing one of my imaginary age selves. Even more than in my earlier works, I was searching for ambiguities and how I can use my vaguely middle-aged body to stage a multiplicity of concepts, phenomena and open questions regarding age(ing). I show seven scenes that each offer a different perspective and relationship to age(ing). The scene I show in a moment is called Improvisation \& Dementia.

The decision to include dementia as a subject in my performance comes from my improvisation practice. In other words, the initial spark neither derives from a case of Alzheimer in my family nor from age theory discourses. It comes from the recurring challenge of finding and maintaining focus and orientation during solo improvisation. Solo improvisation gives me a very specific, partial and situated perspective on the dementia discourse. When I practice solo improvisation, I experience again and again a crisis of disorientation. I struggle to access the compositional knowledge, the improvisational curiosity, the necessary mindfulness that helps to find purpose, focus and orientation in improvised solo dancing. I argue that disorientation is an integral part of improvisation and of an improviser's subjectivity - a subjectivity that tries to be open to the unknown and to change. The research literature on improvisation agrees that the experience of disorientation is not something that experienced practitioners eventually overcome, but that it is one of the shifting constraints, as well as potentials, that improvisation deals with and works with (Albright 2011; Novack 1990; Smith 2003). 


\subsection{Improvisation \& Dementia}

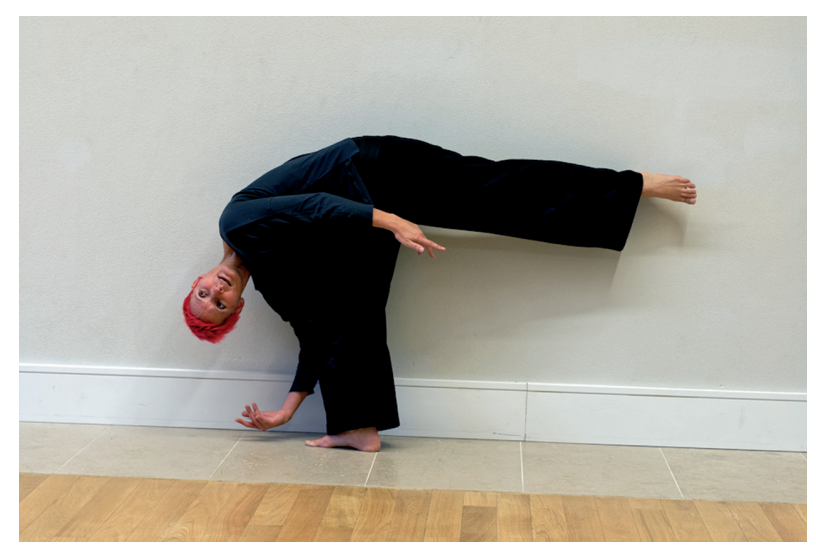

Figure 4: Excerpt from the piece The Fountain of Youth, photo: Peter Derkx]

I take off my reading glasses and I start to dance again. This dance picks up on the movement style I established in the warm-up. I concentrate on and play with each change and movement that I generate from moment to moment. Instead of embodying a character or a story, I invite the audience to follow me, engaging with dance as composing the body in time and space. While dancing, I speak the following words, which is the original text from the scene "Improvisation \& Dementia".

Why do I keep thinking that they have something going on... improvisation and dementia... something like a friendship or kinship?

In a demented state, what is weak and gets progressively weaker is the orientation in space, the orientation in time, and the ability to respond, to be responsive, reactive verbally, physically, socially.

In improvisation I'm dealing with these same issues, again and again, each time I improvise. I'm constantly warming up my orientation. I'm trying to find a relationship here, now; relating myself, here... here... in relation to this... to this...

Which distance? Where? In relation to... you here... me there.

How to adapt? How to place myself... in time?

How long? How fast? How slow? When to start? When to give up? How often... can this make sense?

Improvisation as the never-ending warm up, especially open solo improvisation, painful, painful. I warm up my orientation, my relations into the empty... here... like so... relating... and then - it's gone. So, I start again here... I connect... create some heat... I socialize here, now, and now it's still there... and now it's 
gone. I'm in a loop of constantly building my grounds, my basics into the nothing, and it's OK as long as I keep doing it, but when I stop doing it, it stops doing it.

I need something to respond to, to start moving at all. To respond I first need to sense something, recognize something, feel something.

How does that feel, what can I do with that?

How does that feel, what can I do with that?

How to sense something so clearly that I even have a choice of how to respond, maybe even make up a brand new, totally arty, never-been-there-before kind of a response.

And when doing this I'm very soon in this territory... in dementia research this could be called culturally inappropriate behavior, disinhibited, while I'm still just looking for relationships.

The stage can take much more of this than the street or the family.

Then I walk to the lectern and continue the lecture reading from my script.

\subsection{Analysis and contextualization of the performance excerpt}

I see an interesting tension between embracing states and times of disorientation in dance and mass media discourses that address dementia as the "twenty-first century plague” (Smyth quoted in Swinnen and Sweda 2015, 9). Drawing on Aagje Swinnen's argument that these discourses invoke a kind of "Alzheimer Apocalypse" $(2013,12)$, I contend that the discourse of fear around this age-related illness contributes to establishing a threat-scenario about the looming loss of one's sovereignty and autonomy. Such a threat, in turn, suggests that the selfcontrolled, sovereign, autonomous subject exists in the first place and is perceived as normal. This supposed normality reinforces the demand on the individual to do everything to prevent or delay this loss. As an artistic response, the dance in the scene Improvisation \& Dementia functions as an affirmation of a constantly struggling, ever precarious body-mind, one that accepts disorientation to find orientation, which again is always only temporary.

\section{Epilogue}

I think that is enough for now. To wrap it up, and before opening to your comments and questions, let me say that I'm serious about dancing in academic lectures and about performing my arguments. I am interested in the critical poten- 
tial of bodies and movement, and in giving that a presence instead of just talking about it. On top of that, to keep finding ways to do, to dance, to perform my arguments forces me to keep moving, dancing, working out performances. And this brings me right back to one of the major points of Dancing Age(ing), to strategies of making dance a lifelong physical artistic practice. I want to continue being a dancer, while I also want to share my research. I want myself to be a part of that exciting phenomenon that dancers stay visible and explore dance, show dance and take part in defining dance with a twenty-year-old body, a forty-year-old body, a sixty-year-old body - and if I'm very lucky, an eighty-year-old body.

So, I will keep working on danced lectures, because everything I do is also what I train myself in. And I usually get better at things when I train a lot. Thank you for your attention.

\section{Works cited}

Albright, Ann Cooper. Choreographing Difference: The Body and Identity in Contemporary Dance. Middletown: Wesleyan University Press, 1997.

Albright, Ann Cooper. "Situated Dancing: Notes from Three Decades in Contact with Phenomenology." Dance Research Journal 43.2 (2011): 5-18.

Baumol, William J., Joan Jeffri, and David Throsby. Making Changes: Facilitating the Transition of Dancers to Post-Performance Careers (Research Project). http://www.cpanda.org/data/ a00191/changes.pdf. New York: The aDvANCE Project, 2004 (17 December 2019).

Benjamin, Adam. "Cabbages and Kings: Disability, Dance, and some Timely Considerations." The Routledge Dance Studies Reader. Eds. Alexandra Carter and Janet O’Shea. London: Routledge, 2010. 111-121.

Borgdorff, Henk. The Debate on Research in the Arts. https://www.ahk.nl/fileadmin/down load/ahk/Lectoraten/Borgdorff_publicaties/The_debate_on_research_in_the_arts.pdf. 2006 (17 December 2019).

Bourdieu, Pierre. Distinction: A Social Critique of the Judgment of Taste. Cambridge: Harvard University Press, 1984.

Brayshaw, Teresa, and Noel Witts. Eds. The Twentieth-Century Performance Reader (Third Edition). Abingdon: Routledge, 2014.

Dickinson, Barbara. "Age and the Dance Artist." Staging Age: The Performance of Age in Theatre, Dance, and Film. Eds. Valerie Barnes Lipscomb, and Leni Marshall. New York: Palgrave Macmillan, 2010. 191-206.

Dümcke, Cornelia. Transition Zentrum Tanz in Deutschland (TZTD), Projektstudie zur Modellentwicklung. http://stiftung-tanz.com/wordpress/wp-content/uploads/2013/02/ Workshop-zur-Gr\%C3\%BCndung.pdf. 2008 (17 December 2019).

Formosa, Marvin. "Positive Aging in an Age of Neo-Liberalism." The Ages of Life: Living and Aging in Conflict? Eds. Ulla Kriebernegg and Roberta Maierhofer. Bielefeld: transcript, 2013. 21-35.

Gullette, Margaret Morganroth. Aged by Culture. Chicago: University of Chicago Press, 2004. 
Haller, Miriam. "Aging Studies und Cultural Studies: Inter- und Transdisziplinarität in kulturwissenschaftlichen Alternsstudien.” Transdisziplinäre Alter(n)sstudien: Gegenstände und Methoden. Eds. Ines Maria Breinbauer, Dieter Ferring, Miriam Haller, and Hartmut Meyer-Wolters. Würzburg: Königshausen \& Neumann, 2010. 231-256.

Haller, Miriam. “Ambivalente Subjektivationen: Performativitätstheoretische Perspektiven auf die Transformation von Alters- und Geschlechternormen im geronto-feministischen Diskurs." Alterswelt und institutionelle Strukturen. Eds. Miriam Haller, Hartmut Meyer-Wolters, and Frank Schulz-Nieswandt. Würzburg: Königshausen \& Neumann, 2013. $19-36$.

Hoghe, Raimund. “Den Körper in den Kampf werfen.” Performance: Positionen zur zeitgenössischen szenischen Kunst. Eds. Gabriele Klein and Wolfgang Sting. Bielefeld: transcript, 2005. 51-57.

Koteen, David, and Nancy Stark Smith. Caught Falling: The Confluence of Contact Improvisation, Nancy Stark Smith, and Other Moving Ideas. Northampton: Contact Editions, 2008.

Levine, Mindy N. Beyond Performance: Building a Better Future for Dancers and the Art of Dance. http://www.iotpd.org/upl/advocacy-report-beyond-performance-pdf.pdf. 2005 (17 December 2019).

Maierhofer, Roberta. "An Anocritical Reading of American Culture: The Old Woman as the New American Hero." Journal of Aging, Humanities and the Arts 1.1-2 (2007): 23-33.

Martin, Susanne. JULIO (Performance series 2003-2006). https://vimeo.com/showcase/ 3608339/video/158234066 (17 December 2019).

Martin, Susanne. Rosi tanzt Rosi (Performance series 2007-2009). https://vimeo.com/show case/3608339/video/68854029 (17 December 2019).

Martin, Susanne. The Fountain of Youth (Performance 2013-). https://vimeo.com/showcase/ 3608339/video/130871033 (17 December 2019).

Martin, Susanne. The Fountain of Age (Performance 2015-). https://vimeo.com/showcase/ 3608339/video/142264906 (17 December 2019).

Martin, Susanne. Dancing Age(ing): Rethinking Age(ing) in and Through Improvisation Practice and Performance. Bielefeld: transcript, 2017.

Nelson, Robin. Ed. Practice as Research in the Arts: Principles, Protocols, Pedagogies, Resistances. Basingstoke: Palgrave Macmillan, 2013.

Novack, Cynthia J. Sharing the Dance: Contact Improvisation in American Culture. Madison: University of Wisconsin Press, 1990.

Smith, Nancy Stark. "Life Scores." Taken by Surprise: A Dance Improvisation Reader. Eds. Ann Cooper Albright and David Gere. Middletown: Wesleyan University Press, 2003. 245-254.

Schwaiger, Elisabeth. Ageing, Gender, Embodiment and Dance: Finding a Balance. New York: Palgrave Macmillan, 2012.

Swinnen, Aagje, and John A. Stotesbury. Eds. Aging, Performance and Stardom: Doing Age on the Stage of Consumerist Culture. Berlin: Lit, 2012.

Swinnen, Aagje. "Van Stereotiepe Beeldvorming naar Dementievriendelijk Samenleven." Delen in Dementie: Onderzoeksreflecties. Eds. Ruud Hendriks, Annette Hendrikx, Ike Kamphof, and Aagje Swinnen. Maastricht: University Maastricht, 2013. 12-17.

Swinnen, Aagje, and Mark Schweda. Eds. Popularizing Dementia: Public Expressions and Representations of Forgetfulness. Bielefeld: transcript, 2015. 
Wainwright, Steven P., and Brian S. Turner. "Just Crumbling to Bits? An Exploration of the Body, Aging, Injury and Career in Classical Ballet Dancers.” Sociology 40.2 (2006a): 237-255.

Wainwright, Steven P., and Brian S. Turner. "Varieties of Habitus and the Embodiment of Ballet." Qualitative Research 6.4 (2006b): 535-558.

Woodward, Kathleen. "Performing Age, Performing Gender." Feminist Formations 18.1 (2006): 162-189. 
